\title{
ДИНАМИЧЕСКОЕ ИССЛЕДОВАНИЕ ВЫЗВАННЫХ ПОТЕНЦИАЛОВ В КЛИНИЧЕСКОЙ ПРАКТИКЕ У ПАЦИЕНТОВ С РАССЕЯННЫМ СКЛЕРОЗОМ
}

\author{
${ }^{2}$ Ширалиева Р.К., ${ }^{1}$ Гусейнова С.К., ${ }^{1}$ Несруллаева Н.А.* \\ ${ }^{1}$ Начиональньй центр офтальмологии им. акад. 3.А. Алиевой, Баку; \\ ${ }^{2}$ Кафедра нервных болезней Азербайджанского Государственного Института Усовершен- \\ ствования врачей им. А. Алиева
}

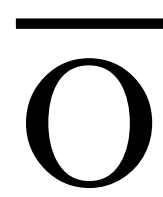

сновой патологического процесса при рассеянном склерозе (РС) является демиелинизация и вследствии этого ухудшение проведения афферентации по нервам и сенсорным путям в мозге.

Демиелинизация аксонов ЦНС при РС ранее считалась необратимой, однако в литературе имеются все увеличивающиеся доказательства процесса ремиелинизации, который происходит в течение определенного периода времени после процесса демиелинизации. В работах ряда авторов [6,7,9] отмечалось, что после первоначального разрушения олигодендроцитов и миелина, в течение нескольких недель или месяцев, сохранившиеся олигодендроциты или те, которые дифференцировались от мигрирующей клетки-предшественника, начинают пролиферировать, и образуется новый миелин. Процессы де - и ремиелинизации могут развиваться в одно и то же или в различное время, в пределах одного и того же патологического процесса, и проявление дефекта ЦНС будет определяться балансом между этими двумя процессами. Возможность ремиелинизации при РС подтвержается электрофизиологическими методами исследованиями, однако в литературе нет четких данных о времени и распространенности процесса ремиелинизации. После острого случая ОН, латентность зрительно вызванных потенциалов обычно пролонгируется, и патология может оставаться на многие годы [2,7 ].Тем не менее, в нескольких исследованиях, в которых пациенты с ОН были обследованы на вопрос повторных случаев [1,9], или в которых были *email:nnaida@mail.ru сравнены протестированные независимые группы пациентов в различные периоды после острого ОН, приводятся доказательства укорочения латентности ЗВП $[1,4,8]$. Хотя полный возврат к нормальным значениям относительно редок [3,5] большинство доказательств предполагают, что тенденция ЗВП латентности к укорочению является превалирующей в течение более 6 месяцев и возможно даже на срок до 3 лет [6,7].

Наиболее значимую информацию об этих процессах предоставляют данные исследования ВП мозга, в том числе наиболее важные ЗВП. Известно, что не существует специфического теста для диагностики РС и диагноз основывается на обнаружении поражений в различных частях ЦНС, возникающих в разное время [10]. Нейрофизиологическое обследование достаточно часто выявляет изменения, протекающие ассимптомно в течении большого периода[4,5 ].

При РС патологические знаки на ВП должны интерпретироваться в клиническом контексте, так же как и другие лабораторные тесты. Особенно полезны ВП по нашим данным и данным литературы для: а) подтверждения ранее возникавших сенсорных симптомов, клинически отсутствующих в настоящее время; б) объективизация звучащих в настоящее время неясных симптомов; в) обнаружение субклинических поражений.

Целью данной работы является проведение динамического анализа данных вызванных потенциалов у больных с рассеянным склерозом в 3-х и 6-месячные интервалы в сроки до 3 лет от начала заболевания. 
Материалы и методы. Нами проведено комплексное клиническое и нейрофизиологическое исследование 65 больных (43 жен-

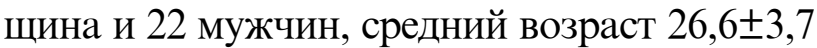
лет - здесь и далее: среднее значение + стандартное отклонение). У 43 больных (66 \%) имелись проявления цереброспинальной формы заболевания, у 22 больных (34 \%) - церебральной формы. У 53 пациентов (82\%) течение РС было ремитирующим, у 12 пациентов (18\%) - вторично - прогрессирующим. Из 65 больных с - 42 пациента (65\%) поступили с изолированным острым оптическим невритом $(\mathrm{OH})$ в период до 2 недель с момента снижения, при этом у 9 пациентов(14\%) отмечался двухсторонний ОН. 23 пациента (35\%) - с оптическим невритом на фоне РС. Все пациенты 2 группы на момент обследования находились в стадии обострения заболевания. С целью верификации заболевания проводилось МРТ головного мозга в режимах Т1 и Т2 взвешенных изображений.

Для диагностики патологических состояний использовались электрофизиологические методы исследования: зрительные вызванные потенциалы на шахматный паттерн и вспышку, слуховые и соматосенсорные вызванные потенциалы.

При исследовании ЗВП на реверсивный шахматный паттерн применялся разный размер клетки: в 20,30,50 угловых минут. При регистрации латентности и амплитуды пиков P100 и P2 во всех отведениях, анализировалась межокулярная разность латентностей.

АСВП регистрировались пиковые латентности: I - ответ от слухового нерва, II - ответ от стволового ядра улитки, III - ответ от ядра верхней оливы, IV - ответ от латеральной петли, V - ответ от нижнего двухолмья и межпиковые интервалы: I-III, III-V, I-V [1, 2, 12].

Исследование ССВП проводили при чрезкожной электрической стимуляции срединного нерва и анализировали латентности стволового ответа (пик Р13) и кортикального ответа (пик Р21). Измеряли время центрального афферентного проведения (ВЦАП)
- межпиковый интервал P13-P21 [3,5].

Выраженность демиелинизации определялась по удлинению латентных периодов основных пиков ВП, изменению их формы, снижению амплитуды или наличию выпадения ответов при блоке проведения. Вышеуказанные параметры важны как для оценки динамики ВП, так и оценки степени нарастание демиелинизации или наоборот, процесса ремиелинизации.

Электрофизиологические исследования проводились на аппарате "Нейро-ЭРГ" фирмы Нейрософт (Россия).

Результаты. У 42 (65\%) был диагностирован изолированный $\mathrm{OH}$ и у 23 пациентов $(35 \%)$ - рассеянный склероз с оптическим невритом, в то время как при повторном осмотре через 3 года количество тех, кому был поставлен диагноз, рассеянный склероз, увеличилось до 15 (48\%). В период повторных визитов у 9 пациентов были выявлены новые симптомы ОН в пораженном глазу, у 8 пациентов новые симптомы на парном глазу, у 6 пациентов появились симптомы заболевания, относящиеся к другим участкам ЦНС, ранее бессимптомным. Сканирования МРТ в 78\% показали изменения во время повторных визитов, указывая на распространение старых поражений или образование новых.

Исследования ЗВП проведено 65 больным с РС, из них у 45 - на предъявление шахматного паттерна (стимулы 20',30',50'), у 20 больных - на вспышечный стимул. Патологическое удлинение латентности P100 на шахматный паттерн в пределах от 112 до 143мкВ отмечалось у 17 больных (37,7\%), удлинение латентности с изменением верхушки пика $\mathrm{P} 100 \mathrm{~W}$ - видной формы, что говорит о грубом нарушении проводимости зрительного нерва у 13 больных (28,8\%). Патологическое снижение амплитуды ответа у 9 больных (20\%). В последних случаях латентность была в пределах нормы. При исследовании ЗВП на вспышку удлинение латентности Р2 отмечалось в пределах 122- 157 мкВ у 8 больных (40\%) и снижение амплитуды 
ответа у 10 больных (50\%). У 2 больных (10\%) на момент обследования ЗВП в пределах нормы. При исследовании ЗВП в фазе клинической ремиссии, сопровождающейся улучшением остроты зрения, выявлена положительная динамика параметров ЗВП в виде достоверного укорочения латентности и амплитуды пиков Р100 и Р2 (таб. 1).

Таблица 1. Динамика изменений параметров зрительных вызванных потенциалов у больных рассеянным склерозом.

\begin{tabular}{|c|c|c|c|c|c|c|c|}
\hline \multirow[b]{2}{*}{$\begin{array}{c}\text { Параметры и } \\
\text { Компоненты } \\
\text { ЗВП }\end{array}$} & \multirow[b]{2}{*}{ Норма } & \multicolumn{6}{|c|}{ Больные рассеянным склерозом } \\
\hline & & $\begin{array}{c}\text { Фаза } \\
\text { обострения } \\
(\mathrm{H}=65)\end{array}$ & $\begin{array}{c}\text { Через } \\
3 \text { месяца } \\
(\mathrm{H}=65)\end{array}$ & $\begin{array}{c}\text { Через } \\
6 \text { месяца } \\
(\mathrm{H}=65)\end{array}$ & $\begin{array}{c}\text { Через } \\
1 \text { год } \\
(\mathrm{H}=65)\end{array}$ & $\begin{array}{l}\text { Через } \\
2 \text { года } \\
(\mathrm{H}=65)\end{array}$ & $\begin{array}{l}\text { Через } \\
3 \text { года } \\
(\mathrm{H}=65)\end{array}$ \\
\hline ЛП Р100( & $100 \pm 3$ & $140,7 \pm 2,3$ & $137,6 \pm 4,7$ & $132,6 \pm 3,5$ & $124,5 \pm 3,0$ & $122,5 \pm 3,0$ & $122,6 \pm 3,1$ \\
\hline A P100 (мкВ) & $9,8 \pm 3,13$ & $5,31 \pm 0,8$ & $5,82 \pm 0,7$ & $6,86 \pm 0,5$ & $7,2 \pm 0,6$ & $7,2 \pm 0,4$ & $7,2 \pm 0,3$ \\
\hline $\begin{array}{l}\text { ЛП Р2 (мс) } \\
\text { А Р2 (мкВ) }\end{array}$ & $\begin{array}{l}100 \pm 15 \\
10,1 \pm 5,5\end{array}$ & $\begin{array}{c}144,7 \pm 4,31 \\
3,7 \pm 0,6\end{array}$ & $\begin{array}{c}146, \text { Л } \pm 7,5 \\
3,7 \pm 0,6\end{array}$ & $\begin{array}{c}143,1 \pm 2,5 \\
4, \text { Л } 0,6\end{array}$ & $\begin{array}{c}138,1 \pm 2,3 \\
5, \text { Л } 2 \pm 0,8\end{array}$ & $\begin{array}{c}131,1 \pm 2,9 \\
4, \text { Л } 0,6\end{array}$ & $\begin{array}{c}131,2 \pm 2,7 \\
4, \text { Л } \pm 0,5\end{array}$ \\
\hline $\begin{array}{l}\text { Межокулярная } \\
\text { разница (мс) }\end{array}$ & $<6,16$ & 7,л $\pm 0,2$ & $8,35 \pm 0,6$ & $7,7 \pm 0,8$ & $7,35 \pm 0,4$ & $7,33 \pm 0,6$ & $7,23 \pm 0,7$ \\
\hline
\end{tabular}

Примечание: н-количество обследованных; достоверные различия $(\mathrm{p}<0.05)$

Но необходимо заметить, что данные параметры сохраняют достоверные отличия от соответствующих показателей контрольной группы, т.е. они не достигают нормальных значений в фазе клинической ремиссии, что может свидетельствовать о неполном восстановлении структуры и функции волокон зрительных нервов.

При исследовании АСВП у всех пациентов в фазе обострения отмечены изменения количественных и качественных характеристик параметров ВП: удлинение латентных периодов III и В пиков и снижение ам- плитуды В пика и тенденция к увеличению межпикового интервала III-V (табл.2). Изменение формы IV-V пиков выявлено в 5ти наблюдениях $(7,6 \%)$, межполушарная асимметрия- у 4-х пациентов $(6,1 \%)$. Выявленные изменения свидетельствовали о нарастании признаков демиелинизации у 30 пациента (47\%) (таб. 4). При обследовании АСВП в 23\% были отмечены признаки ремиелинизации с улучшением параметров пиков и межпикового интервала III-V, в 20 \% случаев АСВП в динамике не претерпевали каких-либо изменений (табл.4).

Таблица2. Динамика изменений показателей акустических вызванных потенциалов у больных рассеянным склерозом.

\begin{tabular}{|c|c|c|c|c|c|c|c|}
\hline \multirow[b]{2}{*}{$\begin{array}{c}\text { Параметры и } \\
\text { компоненты } \\
\text { АСВП }\end{array}$} & \multirow[b]{2}{*}{ Норма } & \multicolumn{6}{|c|}{ Больные рассеянным склерозом } \\
\hline & & \begin{tabular}{|c|} 
Фаза \\
обострения \\
$(\mathrm{H}=65)$
\end{tabular} & $\begin{array}{c}\text { Через } \\
3 \text { месяца } \\
(\mathrm{H}=65)\end{array}$ & $\begin{array}{c}\text { Через } \\
6 \text { месяца } \\
(\mathrm{H}=65)\end{array}$ & $\begin{array}{c}\text { Через } \\
1 \text { год } \\
(\mathrm{H}=65)\end{array}$ & $\begin{array}{l}\text { Через } \\
2 \text { года } \\
(\mathrm{H}=65)\end{array}$ & $\begin{array}{l}\text { Через } \\
3 \text { года } \\
(\mathrm{H}=65)\end{array}$ \\
\hline $\begin{array}{l}\text { пик I ЛП (мс) } \\
\text { пик I A (мкВ) }\end{array}$ & $\begin{array}{c}1,7 \pm 0,15 \\
0,2+0,02\end{array}$ & $\begin{array}{l}1,5 \pm 0,54 \\
0,2 \pm 0,02\end{array}$ & $\begin{array}{l}1,5 \pm 0,03 \\
0,2 \pm 0,02\end{array}$ & $\begin{array}{l}1,5 \pm 0,03 \\
0,2 \pm 0,02\end{array}$ & $\begin{array}{c}1,67 \pm 0,23 \\
0,2 \pm 0,02\end{array}$ & $\begin{array}{c}1,67 \pm 0,13 \\
0,2 \pm 0,02\end{array}$ & $\begin{array}{c}1,67 \pm 0,130 \\
2 \pm 0,02\end{array}$ \\
\hline $\begin{array}{l}\text { пик III ЛП (мс) } \\
\text { пик III А (мкВ) }\end{array}$ & $\begin{array}{l}3,9 \pm 0,19 \\
0,12 \pm 0,02\end{array}$ & $\begin{array}{l}4,2 \pm 0.09 \\
0,1 \pm 0,01\end{array}$ & $\begin{array}{l}4,1 \pm 0.09 \\
0,1 \pm 0,01\end{array}$ & $\begin{array}{l}4,4 \pm 0.09 \\
0,1 \pm 0,01\end{array}$ & $\begin{array}{l}4,9 \pm 0,04 \\
0,1 \pm 0,02\end{array}$ & $\begin{array}{l}4,9 \pm 0.09 \\
0,1 \pm 0,01\end{array}$ & $\begin{array}{l}4,9 \pm 0.09 \\
0,1 \pm 0,01\end{array}$ \\
\hline $\begin{array}{l}\text { пик V ЛП (мс) } \\
\text { пик V А (мкВ) }\end{array}$ & $\begin{array}{c}5,7 \pm 0,25 \\
0,4+0,02\end{array}$ & $\begin{array}{c}5,9 \pm 0,1 \\
0,4 \pm 0,03\end{array}$ & $\begin{array}{c}5,9 \pm 0,1 \\
0,4 \pm 0,03\end{array}$ & $\begin{array}{c}5,9 \pm 0,1 \\
0,4 \pm 0,03\end{array}$ & $\begin{array}{l}5,9 \pm 0,08 \\
0,3 \pm 0,02\end{array}$ & $\begin{array}{c}5,9 \pm 0,1 \\
0,4 \pm 0,03\end{array}$ & $\begin{array}{c}5,9 \pm 0,1 \\
0,4 \pm 0,03\end{array}$ \\
\hline \multicolumn{8}{|c|}{ Межпиковые интервалы } \\
\hline I-III (Mc) & $2,18 \pm 0,03$ & $2,4 \pm 0,09$ & $2,4 \pm 0,09$ & $2,4 \pm 0,09$ & $2,2 \pm 0,09$ & $2,2 \pm 0,01$ & $2,3 \pm 0,031$ \\
\hline $\mathrm{I}-\mathrm{V}(\mathrm{Mc})$ & $4,1 \pm 0,03$ & $4,3 \pm 0,1$ & $4,3 \pm 0,1$ & $4,3 \pm 0,1$ & $4,6 \pm 0,1$ & $4,6 \pm 0,1$ & $4,6 \pm 0,4$ \\
\hline III-V (Mc) & $1,92 \pm 0,02$ & $1,81 \pm 0,07$ & $1,79 \pm 0,05$ & $1,91 \pm 0,06$ & $1,91 \pm 0,07$ & $1,91 \pm 0,07$ & $1,81 \pm 0,05$ \\
\hline
\end{tabular}


При исследовании ССВП у всех пациентов в фазе обострения отмечены следующие изменения параметров ВП (таб.3). При анализе ССВП с срединного нерва у больных Пъ в фазе обострения выявлено увеличение латентного периода пика Р25 по сравнению с нормой и тенденция к увеличению латентного периода пика Н20, которые отражают активность таламуса, таламокортикальной радиации и коры постцентральной извилины. Кроме того, обнаружено достоверное снижение амплитуды пиков Н20 и Н13,изменение формы ответа определялось у 4-х больных $(6,1 \%)$ в виде слабой дифференцировки пиков Н20 и Р25(таб.3,4).

Таблица 3. Динамика изменений показателей соматосенсорных вызванных потенциалов срединного нерва у больных рассеянным склерозом

\begin{tabular}{|c|c|c|c|c|c|c|c|}
\hline \multirow[b]{2}{*}{$\begin{array}{c}\text { Компоненты и } \\
\text { параметры } \\
\text { ССВП }\end{array}$} & \multirow[b]{2}{*}{ Норма } & \multicolumn{6}{|c|}{ Больные рассеянным склерозом } \\
\hline & & \begin{tabular}{|c|} 
Фаза \\
обострения \\
$(\mathrm{H}=65)$
\end{tabular} & $\begin{array}{c}\text { Через } \\
3 \text { месяца } \\
(\mathrm{H}=65)\end{array}$ & $\begin{array}{c}\text { Через } \\
6 \text { месяца } \\
(\mathrm{H}=65)\end{array}$ & $\begin{array}{c}\text { Через } \\
1 \text { год } \\
(\mathrm{H}=65)\end{array}$ & $\begin{array}{l}\text { Через } \\
2 \text { года } \\
(\mathrm{H}=65)\end{array}$ & $\begin{array}{l}\text { Через } \\
3 \text { года } \\
(\mathrm{H}=65)\end{array}$ \\
\hline $\begin{array}{l}\text { Пик Н9 ЛП (мс) } \\
\text { Амп.(мВ) }\end{array}$ & $\begin{array}{l}9,6 \pm 0,7 \\
5,4 \pm 2,5\end{array}$ & $9,3 \pm 0,1$ & $9,3 \pm 0,1$ & $9,5 \pm 0,2$ & $9,3 \pm 0,1$ & $9,3 \pm 0,1$ & $9,5 \pm 0,1$ \\
\hline $\begin{array}{l}\text { Пик Н } 11 \text { ЛП.(мс) } \\
\text { Амп.(мВ) }\end{array}$ & $\begin{array}{c}11,0+0,2 \\
0,7+0.2\end{array}$ & $\begin{array}{l}11.3 \pm 0,1 \\
0,5 \pm 0,1\end{array}$ & $\begin{array}{c}11.3 \pm 0,1 \\
0,5 \pm 0,1\end{array}$ & $\begin{array}{c}11.4 \pm 0,3 \\
0,3 \pm 0,1\end{array}$ & $\begin{array}{c}11.3 \pm 0,1 \\
0,5 \pm 0,1\end{array}$ & $\begin{array}{l}1.3 \pm 0,1 \\
0,5 \pm 0,1\end{array}$ & $\begin{array}{l}1.2 \pm 0,1 \\
0,5+0,1\end{array}$ \\
\hline $\begin{array}{l}\text { Пик Н13 ЛП.(мс) } \\
\text { Амп.(мкВ) }\end{array}$ & $\begin{array}{c}13,2 \pm 0,8 \\
0,4 \pm 0.2\end{array}$ & $\begin{array}{c}13,0 \pm 0,1 \\
0,6 \pm 0,1\end{array}$ & $\begin{array}{l}13,0 \pm 0,1 \\
0,6 \pm 0,23\end{array}$ & $\begin{array}{c}13,4 \pm 0,5 \\
0,7 \pm 0,6\end{array}$ & $\begin{array}{c}13,0 \pm 0,1 \\
0,7 \pm 0,6\end{array}$ & $\begin{array}{c}13,0 \pm 0,1 \\
0,7 \pm 0,5\end{array}$ & $\begin{array}{c}13,0 \pm 0,1 \\
0,7 \pm 0,5\end{array}$ \\
\hline Пик Н14 ЛП.(мс) & $14,8 \pm 0,5$ & $14,4 \pm 0,2$ & $14,4 \pm 0,2$ & $14,7 \pm 0,5$ & $14,4 \pm 0,2$ & $14,4 \pm 0,2$ & $14,4 \pm 0,2$ \\
\hline $\begin{array}{l}\text { Пик Н20 ЛП.(мс) } \\
\text { Амп.(мкВ) }\end{array}$ & $\begin{array}{c}18,9 \pm 1,0 \\
2,8 \pm 1,6\end{array}$ & $\begin{array}{c}20,4 \pm 0,6 \\
2,9 \pm 0,4 \\
\end{array}$ & $\begin{array}{l}20,4 \pm 0,6 \\
2,59+0,4 \\
\end{array}$ & $\begin{array}{l}20,0 \pm 0,5 \\
2,8 \pm 1,4 \\
\end{array}$ & $\begin{array}{c}21,4 \pm 0,6 \\
2,8 \pm 1,4 \\
\end{array}$ & $\begin{array}{c}21,4 \pm 0,6 \\
2,8 \pm 1,4 \\
\end{array}$ & $\begin{array}{c}21,3 \pm 0,4 \\
2,8 \pm 1,4 \\
\end{array}$ \\
\hline $\begin{array}{l}\text { Пик Р23 ЛП(мс) } \\
\text { Амп.(мкВ) }\end{array}$ & $\begin{array}{l}23,1 \pm 0,38 \\
1,85 \pm 0,69\end{array}$ & $\begin{array}{c}26,15 \pm 0,7 \\
2,5 \pm 0,4\end{array}$ & $\begin{array}{c}25,1 \pm 0,8 \\
2,5 \pm 0,4\end{array}$ & $\begin{array}{c}2,51 \pm 0,6 \\
2.3 \pm 0,3\end{array}$ & $\begin{array}{c}25,1 \pm 0,7 \\
2,3 \pm 0,5\end{array}$ & $\begin{array}{c}25,1 \pm 0,8 \\
2,3 \pm 0,4\end{array}$ & $\begin{array}{c}26,1 \pm 0,8 \\
2,3 \pm 0,4\end{array}$ \\
\hline $\begin{array}{l}\text { Асимметрия } \\
\text { ВЦАП (мс) }\end{array}$ & $1,55 \pm 0,78$ & $1,7 \pm 0,76$ & $1,7 \pm 0,78$ & $1,65 \pm 0,98$ & $1,65 \pm 0,98$ & $1,65 \pm 0,78$ & $1,64 \pm 0,79$ \\
\hline
\end{tabular}

При повторном исследовании в фазе клинической ремиссии количественная и качественная характеристика ССВП с срединного нерва в 50 \% указывает на ухудшение параметров ответа на разном уровне: коры или спинально-стволовом уровне, что свидетельствовало о наличии нарастания процесса демиелинизации и только в 17\% при повторном обследовании ССВП было отмечено улучшение ответов и признаки ремиелинизации. (Таблица 4).

Как следует из таблицы 4 при исследовании динамики ВП в 22 наблюдениях (37\%) параллельно нарастанию клинической картины отмечалось и ухудшение параметров ВП - нарастание демиелинизирующего процесса. Ни в одном случае не отмечено ухудшения доходящего до наличия блока проведения.

Таблица 4.Анализ результатов исследования ВП в динамике у больных РС

\begin{tabular}{|l|c|c|c|c|c|c|}
\hline \multirow{2}{*}{\multicolumn{1}{c|}{ Изменения ВП в динамике }} & \multicolumn{2}{c|}{ ЗВП } & \multicolumn{2}{c|}{ АСВП } & \multicolumn{2}{c|}{ ССВП } \\
\cline { 2 - 7 } & $\begin{array}{c}\text { Число } \\
\text { наблюдений }\end{array}$ & $\begin{array}{c}\text { Число } \\
\text { наблюдений }\end{array}$ & $\begin{array}{c}\text { Число } \\
\text { наблюдений }\end{array}$ & $\%$ \\
\hline Без изменений (сходные изменения ВП) & 8 & 12 & 20 & 30 & 21 & 33 \\
\hline Улучшение (наличие ремиелинизации) & 33 & 52 & 15 & 23 & 11 & 17 \\
\hline Ухудшение (нарастание демиелинизации) & 24 & 37 & 31 & 47 & 32 & 50 \\
\hline
\end{tabular}


В 33 наблюдениях (52\%) по тем или иным параметрам отмечалась положительная динамика, однако чаще не доходящая до полной нормализации параметров ответов. В динамике при обследовании слуховых стволовых ВП (АСВП) в 47 \% отмечено ухудшение параметров АСВП и нарастание признаков демиелинизации и только у $23 \%$ были отмечены признаки ремиелинизации с улучшением параметров АСВП, в динамике при исследовании параметров АСВП в 30\% случаев каких - либо изменений выявлено не было.

Аналогично при обследовании динамики у этой когорты больных и соматосенсорных ВП - ССВП в 50 \% было показано ухудшение параметров ответа на разном уровне коры или спинально-стволовом уровне и наличие признаков нарастания демиелинизации и только в 17\% у больных с дополнительным обследованием и ССВП было отмечено улучшение ответов и признаки ремиелинизации.

T.о., при динамическом обследовании АСВП или ССВП, параметры ВП или слабо изменялись, или давали ухудшение, т.е. нарастание демиелинизации. В меньшем \% случаев, по сравнению с динамикой ЗВП, отмечались улучшение параметров и имелись процессы ремиелинизации: соответственно $52 \%$ для ЗВП $23 \%$ для АСВП и только 17\% для ССВП. Т.о. более отчетливые процессы ремиелинизации по данным ВП отмечались при анализе проведения по зрительным путям (таб.4). Таким образом, в течение первых 3 лет после $\mathrm{OH}$ в зрительном нерве активны два противоположных процесса: с одной стороны, восстановительный процесс ремиелинизации, и с другой стороны, бессимптомно развивающийся процесс демиелинизация и/или дегенерации аксонов.

Ремиелинизация является наиболее правдоподобной причиной прогрессирующего укорочения первоначально пролонгированных латентностей ЗВП, которые продолжаются в течение, по крайней мере, 3 лет, сопровождаемые легким функциональным улучшением (в течение первого года). В течение второго года существует незначительное, или вообще отсутствует функциональное улучшение, хотя ЗВП латентности в среднем продолжают понижаться. В третий год отмечается дальнейшее укорочение ЗВП латентности, однако амплитуды ЗВП могут несколько ухудшаться. Частичное объяснение диссоциации между латентностью ЗВП и зрительной функцией может быть такое: остаточный зрительный дефицит после разрешение острой воспалительной фазы возможен из-за постоянной потери аксонов.

В качестве примера приведем данные исследования изменений ЗВП у пациентки с ОН в динамике в острой стадии и в отдаленном периоде через 3 месяца (рис. 1). Амплитуда ответов не снижена.

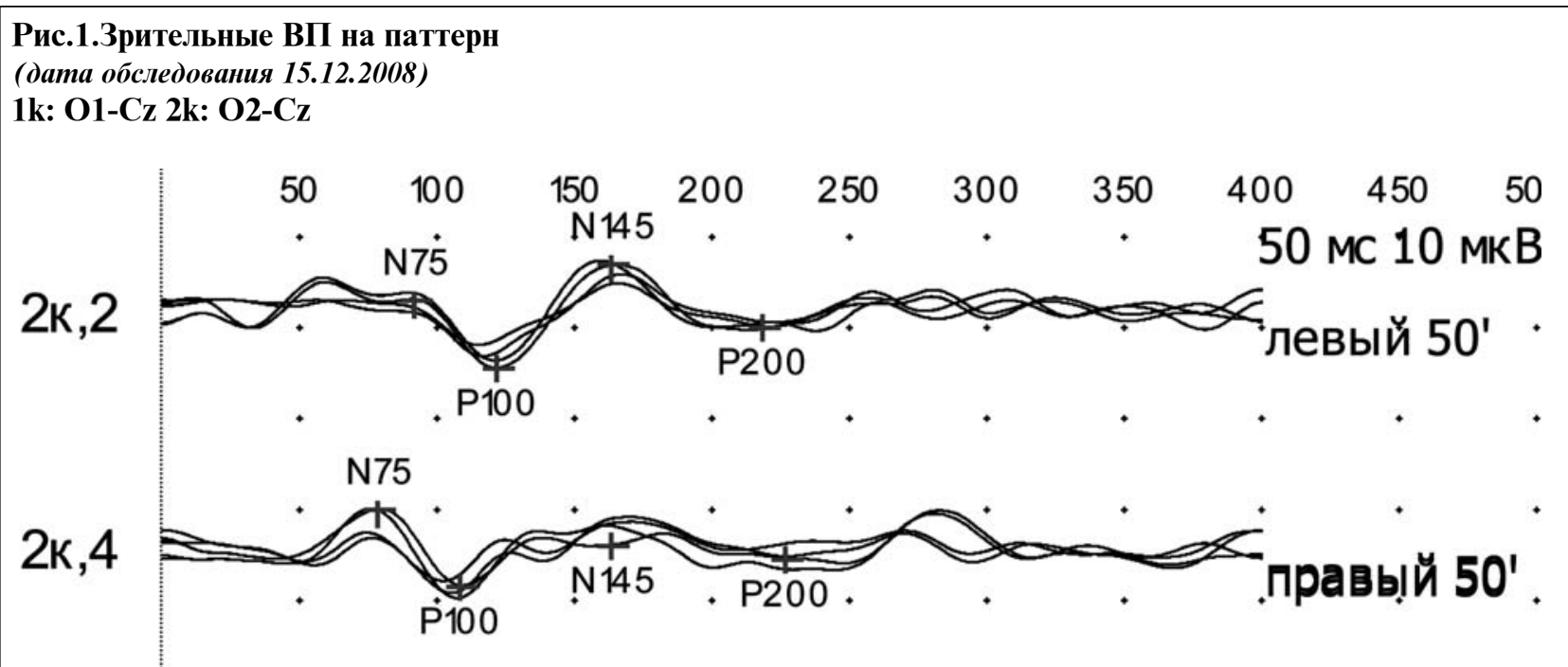


В клинической картине отмечалась нечеткость и затуманивание изображения при фиксации взгляда, при остроте зрения 1 на правый глаз и небольшого снижения (до 0,7) на левый. На МРТ признаки демиелинизирующего заболевания. В картине ЗВП на шахматный реверсивный паттерн наблюдаются значительные изменения: на левый глаз удлинение латентности до 122 мс пика Р100 (норма 3 сигма до 102 мс), на правый глаз - до 108 мс. Отмечается значительная межокулярная разница параметров ответа: на 14 мс в латентности P100, за счет большего замедления проведения по левому зрительному нерву, и небольшого снижения амплитуды ответа на правом.

На фоне терапии у больной П.Е. отмечалось улучшение показателей ЗВП (рис.2).

Рис.2. Пример ЗВП на РШП у больной. П.Е., 31 год с диагнозом РС , вторично-проградиентное течение после лечения пульс терапии (дата обследования: 23.01.2009)

$1 \mathrm{k}: \mathrm{O} 1-\mathrm{Cz} 2 \mathrm{k}$ : O2-Cz

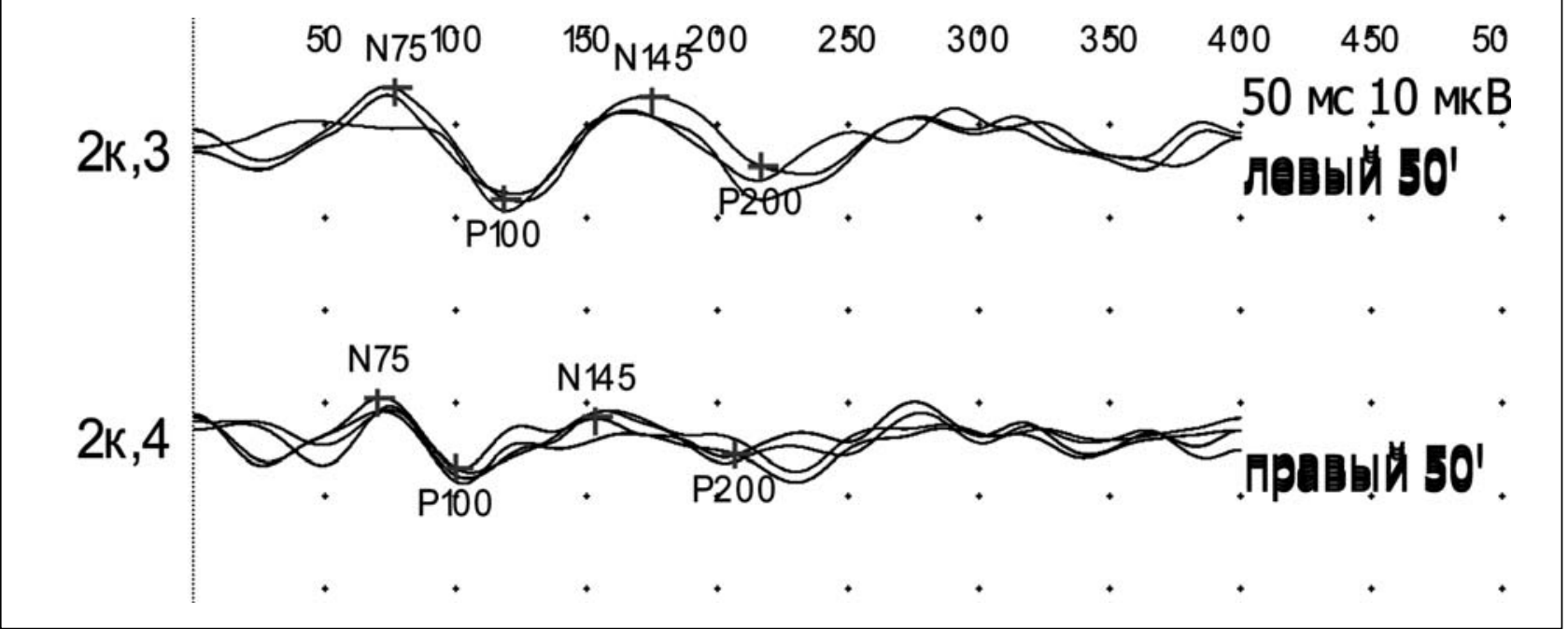

Обращает внимание на снижение ЛП пика Р100 с 122 до 118 мс слева (для пика Н75, также снижены с 92 мс до 77 мс) и до 100 мс становиться в пределах нормы (102

мс) до лечения 108 мс. Аналогичная закономерность наблюдается при исследовании ЗВП на мелкую клетку (рис. 4) в динамике

Рис 3.А, Б ЗВП на мелкую клетку в динамике на фоне терапии у больной П.Е. 31 года. А.1 обследование (15.12.08)

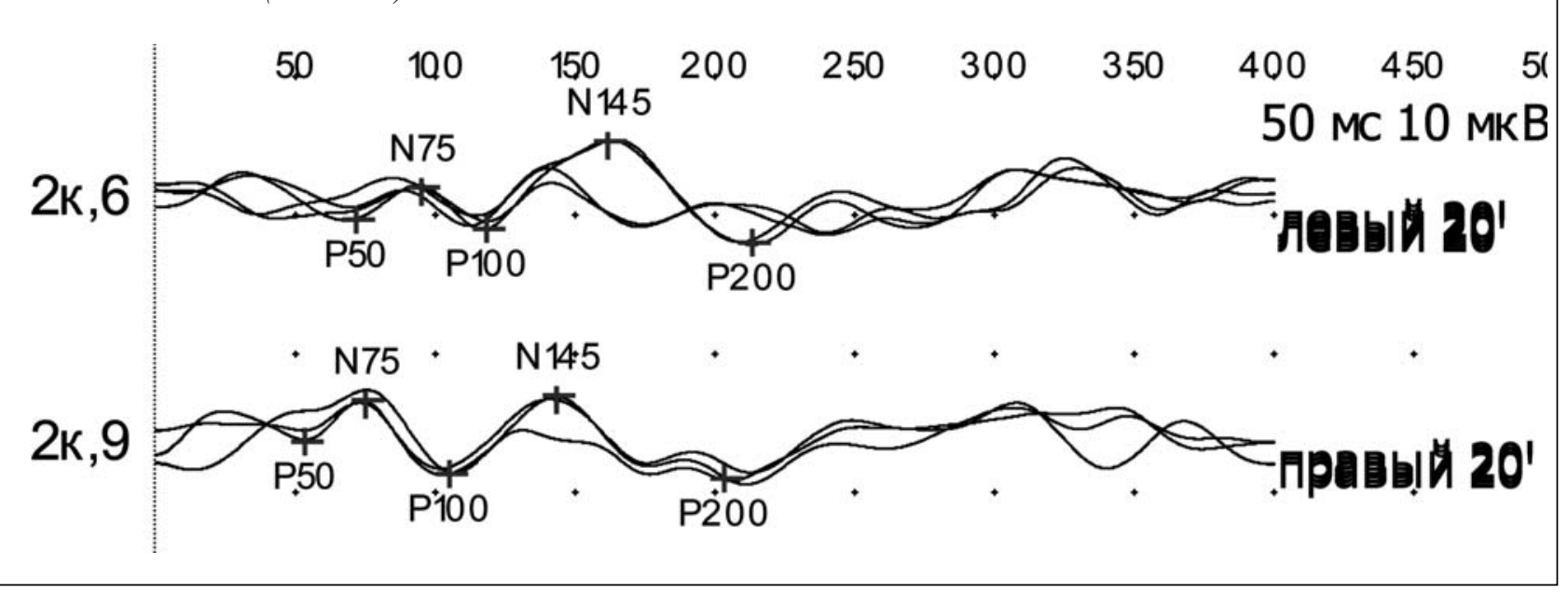




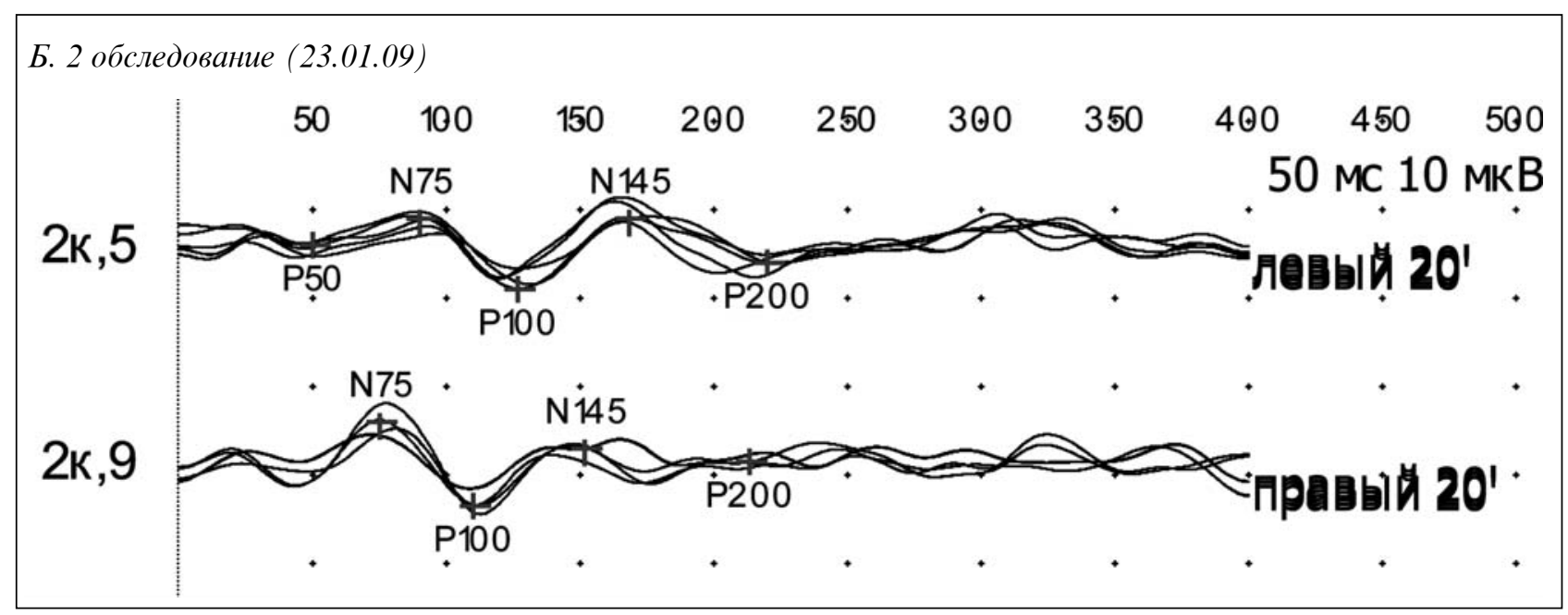

Как видно из рисунка 3, на фоне терапии отмечается уменьшение ЛП коркового пика Р100 как при стимуляции левого глаза, так и правого глаза с увеличением амплитуды ответов больше слева.

T.о., более отчетливый процесс ремиелинизации можно видеть при анализе проведения в динамике по ВП по зрительным путям. При положительной динамике, связанной с процессами ремиелинизации, отмечалось укорочение ЛП вплоть до полной нормали-

\section{ЛИТЕРАТУРА}

1. Байдина Е.В. Лабильность неврологических симптомов при РС( клиническое, электрофизиологическое и бихимическое исследование): автореф. дис. ... канд. мед. наук. М., 2004

2. Бархатова В.П. Патофизиология демиелинизирующего процесса// Рассеянный склероз. Избранные вопросы теории и практики М.- 2000.- 185.

3. Гнездицкий В.В. Нейрофизиологические методы в неврологии //Нервные болезни/Под редакцией М.Н Пузина.М. Медицина, 2002, стр. 92-132

4. Гнездицкий В.В. Вызванные потенциалы мозга в клинической практике. 2 доп.изд.М.:Медпресс-информ, 2003 г. , 263 стр

5. Гнездицкий В.В., Корепина О.С. Атлас по вызванным потенциалам мозга.Иваново,2011,532 стр. зации, а также выявлялось улучшение формы ответа, вместо расширенного пика или измененной двугорбой формой кривой с большой хронодисперсией, появлялась одномодальная форма с одним пиком. Т.о., при наличии блока проведения и отсутствия ответов при динамическом наблюдении мы могли видеть появление, хотя и измененного ответа с повышенной латентностью на паттерную стимуляцию, что также указывает на протекающий процесс ремиелинизации.

6. Brusa A. et al. Long-term remyelitenationa after optic neuritis. A 2-year visual evoked potential and psychophysical serial study. Brain(2001),124,468-479

7. Brusa A.et al. Long-term recovery and fellow eye deterioration after optic neuritis, determined by serial visual evoked potentials.J.Neurology, 246 (9) 776 - 782.

8. Klistorner A. Remyelination of optic nerve lesions: spatial and temporal factors. Multiple Sclerosis,2010 vol. 16,№ 7786-795

9. Lucchinetti C.F. et al. Distinct patterns of multiple sclerosis pathology indicates heterogeneity in pathogenesis. Brain Pathology, 1996, 6:243-258.

10. Rossini PM, Zarola F, Floris R, Bernardi G, Perretti A, Pelosi L, et al. Sensory (VEP, BAEP, SEP) and motorevoked potentials, liquoral and magnetic resonance findings in multiple sclerosis. Eur Neurol 1989; 29: 41-7 


\title{
XÜLASə
}

\section{DAĞINIQ SKLEROZLU XəSTӘLӘRINN KLINIK TӘCRÜBӘSINDӘ ÇAĞIRILMIŞ POTENSİALLARIN DINNAMIK TODQIQİ}

\author{
${ }^{2}$ Şirəliyeva R.K., ${ }^{1}$ Hüseynova S.K., ${ }^{1}$ Nosrullayeva N.A. \\ ${ }^{1}$ Akademik Z.Ә. Oliyeva adina Milli oftalmologiya morkazi, Bakı; \\ ${ }^{2}$ O. Oliyev adına Azərbaycan Dövlat Həkimləri Təkmillaşdirmə Institutunun Sinir xəstəlikləri ka- \\ fedrasl, Bakl
}

Təqdim olunmuş işin məqsədi xəstəliyin başlanmasından keçən 3 il müddət ərzində dağınıq sklerozlu xəstələrdə çağırılmış potensialların məlumatlarının 3 və 6 ay aralığında dinamik təhlilinin həyata keçirilməsidir.

Materiallar və metodlar. Bizim tərəfimizdən 65 xəstə (43 kişi və 22 qadın, orta yaş 26,6士3,7 il) klinik və neyrofizioloji cəhətdən tədqiq olunmuşdur. 65 xəstədən 42 -si $(65 \%)$ azalma anından 2 həftə müddətində təcrid olunmuş kəskin optik nefritlə (ON) daxil olmuşdu; bu zaman 9 xəstədə (14\%) ikitərəfli ON qeyd edilmişdi. 23 xəstə (35\%) dağınıq skleroz (DS) fonunda optik nefritlə daxil olmuşdu. Çağırılmış potensialların dinamik tədqiqinin nəticələrinin təhlili görmə çağırılmış potensiallarla (GÇP) müqayisədə akustik gövdə çağırılmış potensiallarının (AGÇP) və somatosensor çağırılmış potensiallarının (SSÇP) əhəmiyyətsiz dərəcədə dəyişməsindən və ya pisləşməsindən xəbər verirdi ki, bu da demielinizasiya prosesinin artmasını göstərirdi. Çağırılmış potensialların parametrlərinin aşkar edilmiş yaxşılaşmaları (müvafiq olaraq GÇP üçün 51\%, AGÇP üçün $23 \%$ və SSÇP üçün yalnız 17\%) cərəyan etməkdə olan remielinizasiya prosesindən xəbər verirdi. Açar sözlər: dağınıq skleroz, çağrılmış potensialla.

\section{SUMMARY}

\section{DYNAMIC STUDY OF EVOKED POTENSIALS IN CLINICAL PRACTICE IN PATIENTS WITH MULTIPLE SCLEROSIS}

\author{
${ }^{2}$ Shiraliyeva R.K., ${ }^{1}$ Guseynova S.K., ${ }^{1}$ Nasrullayeva N.A. \\ ${ }^{1}$ National Ophtalmology Center,named after akad.Z.Aliyeva, Baku; \\ ${ }^{2}$ Azerbaijan State Advanced Training Institute for Doctors, Baku
}

The aim of this work is to carry out a dynamic analysis of evoked potentials in patients with multiple sclerosis in 3 and 6-month intervals for up to 3 years from the onset. Materials and methods. We conducted a comprehensive clinical and neurophysiologic study of 65 patients ( 43 women and 22 men, mean age 26, $6 \pm 3,7$ years). During dynamic examination acoustic evoked potentials (AEP) or somatosensory evoked potentials (SEP), the parameters or slightly changed, or given the deterioration, that is, the growth of demyelination. In a small percent of cases, compared with the dynamics of the visual evoked potentials (VEP), improvements in these parameters were observed and there were processes remyelination: respectively $52 \%$ for VEP, $23 \%$ for SEP and only $17 \%$ for AEP. Thus, more distinct remyelination process according to evoked potentials observed in the analysis of the visual pathways. Key words: multiple sclerosis, evoked potentials.

Redaksiyaya daxil olub: 16.10 .2012

Çapa tövsiyz olunub: 31.10 .2012

Rayçi: R.L.Hasanov, t.e.d. dosent 